\title{
Commuter Train Mode Choice Modelling Using Binary Logit Model
}

\author{
Ryan Septiady \\ Program Studi Teknik Sipil, Universitas Pembangunan Jaya \\ ryan.septiady@upj.ac.id
}

\begin{abstract}
Car production in Malaysia is increase dramatically. This situation created serious impact such as pollution and congestion. The Malaysian government should find a proper solution to prevent the vehicles growth by controlling them and improve public transportation services. The only way to get people switch to public transportation is by improving the public transport system becomes more efficient. To find out the solution, an understanding of traveler behavior by apply mode choice model using binary logit approach is necessary. Stated preferences method was adopted in order to construct hypothetical choice in current and future situations. A total of 250 respondents were selected as the sample based on the research study. This research employed a discrete choice analysis to examine the relationship between the independent variables (travel time, fares, comfort and safety). With variation of trip purpose (school, work, leisure activity, and shopping), model has been developed and tested to check the validity. The result shows that the potential of new train services to compete with the current commuter (KTM) and private car user are quite competitive. This is no doubt due to the characteristics of the respondent to choose a good level of services especially a better comfortability and safety with an affordable price (fares). It can be concluded that scenario 2 has great potential to be implemented since forecasting demand reached above $90 \%$.

Keywords : Public Transportation, Comutter, Train Services
\end{abstract}

\section{INTRODUCTION}

Many developing and developed countries experiencing problems with transportation and some of them were faced in very critical stage. This situation occur not only due to the limited transport infrastructure exists, but is coupled with other problems, such as low incomes, rapid urbanization, limited resources, particularly in the funds, the quality and quantity of data related to transportation, quality of human resource, weak controls on transportation planning, thus making all the problems becomes increasingly worse. Malaysia is a one of developed country in Asia, with dramatically growth in term of economy, infrastructure development, and human resources. The Malaysia is threatened by these infrastructures and economical presented. One of the Malaysia's government concerns is to upgrade public services system such as public transportation to become more efficient and successful.

According to Ofyar (1997), transportation issues and planning techniques revolutionized rapidly since the 1980s. At the time people still facing with transpiration an issue that actually has been occurred since the 1960 s to the 1970 s. In Asia, Malaysia is a rich developing country, which offers the consequences of explosions in both human and motorisation. This has been accompanied by a heavy demand in road traffic and economic cost. In current development, Malaysia still works on providing supply of highway infrastructure. On the other hand, transportation planning in Malaysia becomes part of process that involves the analysis of current travel patterns and the forecasting of structure travel in demand for future patterns. Malaysia is prosperous rapidly growing country with high private vehicle ownership automobile and only approximately of urban travel is by public transport. In order to make restraint on private transport politically feasible, public transports have to be greatly improved. In 2007, it was estimated by OICA (International Organization of Motor Vehicle Manufacture) that there are more than 70,000,000 cars including the vans and trucks. Based on OICA cars production statistic from 2006 there were 40,000,000 the number of passenger cars produced in the world with the increasing of $6.45 \%$ over the year in 2005. It was found that the 
number of vehicle in Malaysia around 441,661 cars of the total break down from 347,971 cars and 93,690 commercial vehicles in 2007 as shown in table 1.1 below.

Table 1. Cars Production Statistic

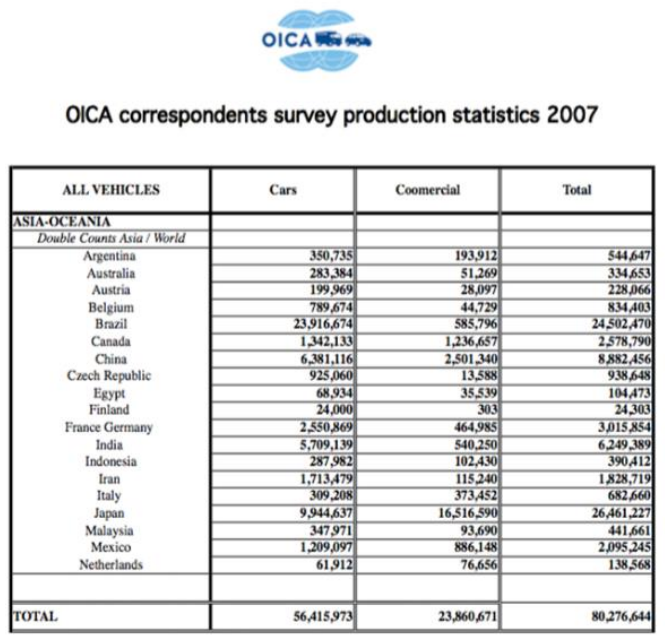

According to Abdullah Nurdeen 2007, Malaysia's rapid growth in population, economy and motorisation has resulted in the number of registered motor vehicles increasing by $8,321,517$ over the 12 years period from 1990 to 2003. In other words, there was a general increase of $54.6 \%$ for all motor vehicle registration in Malaysia.

However, has led to an increasing in road traffic accidents and casualties.

Increasing the capacity of Malaysia's population is hardly to push government make a decision about the functional of public transportation is became more serviceable and suitable for people attraction. In line with that, Resdiansyah (2011) mentioned that, congestion and traffic-related pollution are increasingly becoming major issues in towns and cities worldwide.

This research is concern in one of particular area in Negeri Sembilan, Malaysia called Mantin, this state is a mostly covered by industrial area apart from the capital city of Malaysia which is Kuala Lumpur. Negeri Sembilan is highly evolved state, and therefore the areas around the state are showing progress in the field of property such as housing, road toll, industry and education as well. In 2007, Mantin itself is an isolated area and difficult for people to travelling to Kuala Lumpur just consumes only one public transportation service called Batang Benar Commuter station. In addition, a formal public transport such as train in this area is not encouraging due to the services availability. In order to introduce an efficient train service, an understanding of passenger's behavior towards train service attributes is necessary. By using logit model based on statical model are developed to analyses passenger trade-offs between each attribute and to shed some factors contributing to potential mode change. The finding of this research are expected to further the understanding of passenger's viewpoint on the train service attribute and the results can be used in strategic planning for establishing a proper train service in Negeri Sembilan Malaysia.

\section{RESEARCH METHODOLOGY}

This research is present of discussion of finding result attribute scenario from survey in a speculation based on percentage of the respondents. This method used to complete a thorough the research by using a stated preferences techniques, and the result of the questionnaire is formulated into the model are made to produce the desired percentage in accordance with the filled out by all correspondents. The questionnaires are distributed to the main survey is given limit by a researcher around 250-300 correspondents. In making the survey data to distribute to all targets such as a train passenger in existing location, the method has been used with two of condition circumstances where the passenger must choose the existing services or new services that has been created to raise the quality of the train services.

Basically, in some of various research attributes are defined as the variables 
identification, which described and define the differences between the alternatives services. The attributes may involve such as travel time, waiting time (frequency), cost (in terms of fares), comfort, safety, reliability, interchange, headway and others. But this research conducted such as travel time, frequency, cost, comfortability, and safety.

Table 2. Definitions of Level Attributes

\begin{tabular}{lll}
\hline Attributes & Levels & \\
\hline Travel Time (min) & Fast & 35 \\
& Original & 50 \\
& Slow & 65 \\
Frequency (min) & Frequent & 10 \\
& Original & 20 \\
& Infrequent & 30 \\
\hline \multirow{2}{*}{ Fares (RM) } & High & 6.7 \\
& Normal & 4.7 \\
Comfort & Low & 2.7 \\
& High & Good \\
\hline Safety & Original & Poor \\
& High & Good \\
\hline
\end{tabular}

From Table 2 above, it can be seen that each attribute has a variable level. At travel time, frequency, and fares have three different levels such as the best, normal as an existing condition, and the worst situation. With every 35 minutes duration taken by the train speed the train will come at much faster frequency every 10 minutes in scenario. Normal speed on a commuter is only 50 minutes based on calculated in existing situation with the frequency of train in every 20 minutes and not including for delay. In fact, the normal price of this commuter from Batang Benar to Kuala Lumpur is RM4.7 and it takes around 50 minutes trip. With the hypothetical scenario that is made to raise the standard of public transport services is whether the users of private vehicles will shift to public transport service or not.
The important issue in the design of stated preference experiment is the choice of the context and the measurement scale for the dependent variable. Traditional stated preference methods provide respondent with a set of description of alternatives and ask them to express their preference by sorting the alternatives in decreasing order preference or by giving a rating value for each. To finalize the full factorial design it must be necessary the combination of $3^{2} \times 2^{2}=108$ options, means that there are 3 levels have 2 attributes and another 2 levels consist with 2 attributes. The total of the combination for full factorial is 108 options. When a full factorial design generates too many alternatives adopting a fractional design method can reduce the number. So, that only selection of all possible combination will be presented to the respondent, analytically at the expense of the number of interaction that can be estimate, Kroes (1998). The survey conducted after the data simulation and pilot survey have been analyzed successfully. It will be the final tool is able to provide interpretable and applicable result, has meaning and interest for each respondent. In questionnaire survey given to randomly target, it can be seen how a filling the criteria of respondents. Meanwhile, in this survey there are many trance perception of passenger in accordance with what they think. From this survey result also is view based on passenger purpose and function of the train, for an example, who has to go for school needs, or people who just went by train to the interests of leisure activity, shopping, or just entertainment. In order to produce result and good formative research, conducted methodologies that should run well too in accordance with applicable procedures. The figure 1 shows a breakdown methodology applied in this research begins with a discussion then use the primary literature review that collected from a number of journals, books, and related articles. 


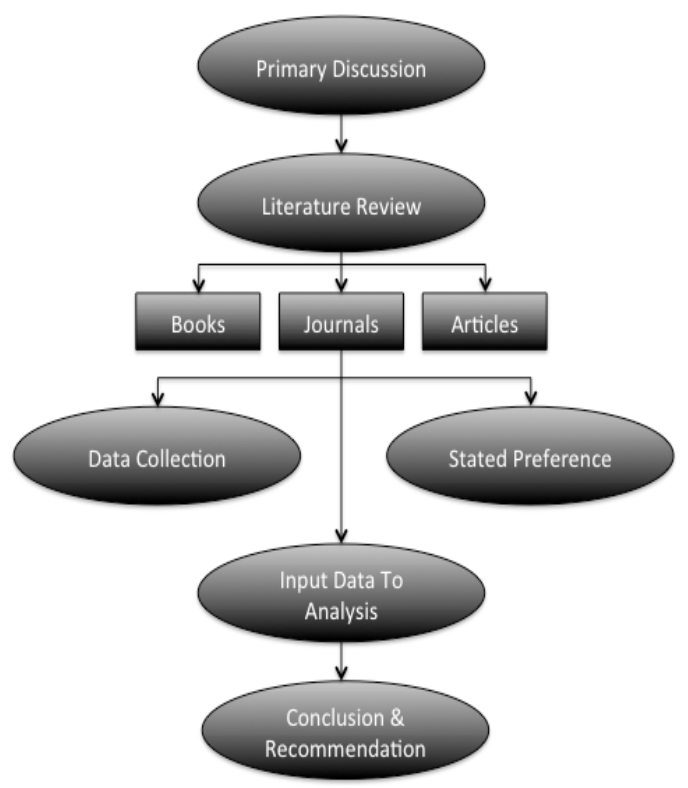

Figure 1. Research Methodology Flow Chart

Collecting data is using questionnaires stated preference techniques based on the passenger behavior. When the data collection was successful according the standard of procedure has been passed, the data will be analyzed by using the Statistical Package for Social Science Software (SPSS) along with the binary logit model of mode choice. In order to measure the relative significance of demographic, socioeconomic and service attributes that influence by passenger choice behaviour.

The scenario designing when full fractional generates too many alternatives adopting a fractional design method can reduce the number. Certain number of scenarios has been defined and simulated as follows as shown in table 3 .

Table 3. Research Scenario Design

\begin{tabular}{llllll} 
Scenario & $\begin{array}{l}\text { Travel } \\
\text { Time }\end{array}$ & $\begin{array}{l}\text { Freque } \\
\text { ncy }\end{array}$ & Fares & Comfort & Safety \\
& Minutes & $\begin{array}{l}\text { Minute } \\
\text { s }\end{array}$ & $\begin{array}{l}\text { Minute } \\
\text { s }\end{array}$ & & \\
$\begin{array}{l}\text { Current } \\
\text { Situation }\end{array}$ & 50 & 20 & 4.7 & Poor & Poor \\
$\mathbf{1}$ & & & & & \\
$\mathbf{2}$ & 50 & 20 & 2.7 & Poor & Poor \\
$\mathbf{3}$ & 50 & 10 & 2.7 & Good & Good \\
$\mathbf{4}$ & 50 & 30 & 2.7 & Poor & Good \\
$\mathbf{5}$ & 35 & 30 & 2.7 & Poor & Poor \\
$\mathbf{6}$ & 35 & 20 & 2.7 & Good & Poor \\
\hline & 35 & 10 & 2.7 & Poor & Poor \\
\hline
\end{tabular}

\section{MODELING DEVELOPMENT AND EVALUATION}

Demographic data provide an essential evidence base for the development and evaluation of public policies. The bottom line is that a country cannot develop without data. Although the term data has technical overtones and important technical issues need to be considered, the more fundamental connection is between good data and good governance. A total of 350 survey forms were collected during the survey day, but a after screening process, 100 incomplete forms were discarded. In total, 250 survey questioners have been analysed.

Table 4. Cumulative Percentage of Age

\begin{tabular}{lllll}
\hline Valid & $\begin{array}{c}\text { Freque } \\
\text { ncy }\end{array}$ & Percent & $\begin{array}{c}\text { Valid } \\
\text { Percent }\end{array}$ & $\begin{array}{c}\text { Cumulativ } \\
\text { e Percent }\end{array}$ \\
\hline$<\mathbf{1 8}$ & 40 & 16.0 & 16.0 & 16.0 \\
\hline $\mathbf{1 9}-\mathbf{3 0}$ & 158 & 63.2 & 63.2 & 79.2 \\
\hline $\mathbf{3 1}-\mathbf{4 0}$ & 37 & 14.8 & 14.8 & 94.0 \\
\hline $\mathbf{4 1}-\mathbf{5 0}$ & 11 & 4.4 & 4.4 & 98.4 \\
\hline$>\mathbf{5 1}$ & 4 & 1.6 & 1.6 & 100.0 \\
\hline Total & 250 & 100.0 & 100.0 & \\
\hline
\end{tabular}

Source: SPSS Software

Figure 2 show the distribution of respondent by age. The highest percentage is the respondent aged between 19 to 30 years which us about $63 \%$ of the total respondent. The second highest is the percentage for respondent aged below 18 years. While, the lowest percentage is the respondent aged below aged above 50 years, which is about $2 \%$ only. From the result above it can be determine that most of the teenagers and adult from 19 years to 30 years old use the train for daily activity.

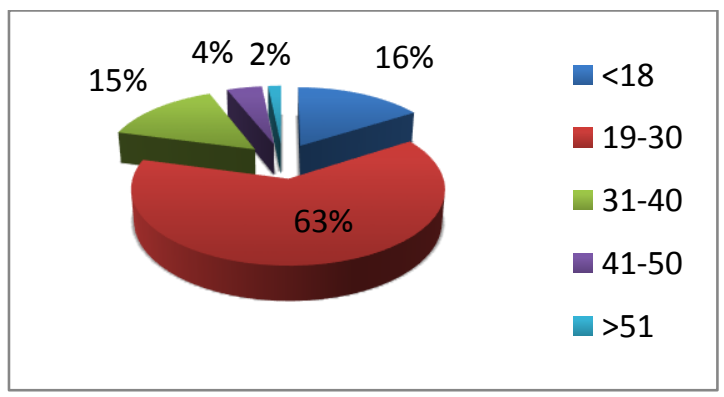

Figure 2. Age Characteristics 
Table 5. Cumulative Percentage of Gender

\begin{tabular}{|l|l|l|l|l|}
\hline Valid & Frequency & Percent & $\begin{array}{l}\text { Valid } \\
\text { Percent }\end{array}$ & $\begin{array}{l}\text { Cumulative } \\
\text { Percent }\end{array}$ \\
\hline Male & 146 & 58.4 & 58.4 & 58.4 \\
Female & 104 & 41.6 & 41.6 & 100.0 \\
Total & 250 & 100.0 & 100.0 & \\
\hline
\end{tabular}

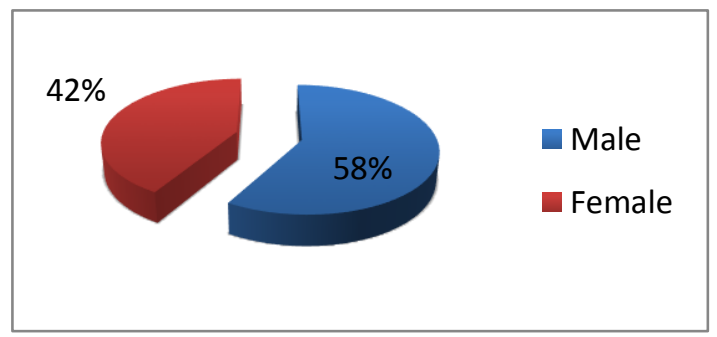

Figure 3. Gender Characteristics

Figure 3 above show the percentage of the respondent by gender. From the pie chart, male respondents comprised of $58 \%$ and $42 \%$ of the total respondents were female. The composition for both gender are relatively similar because the sample was randomly taken.

Malaysia is one of the country have a more than races people, therefore living together such as Malayan people, Chinese, and India. So, the survey based on race in Malaysia questionnaire distributed. From the pie chart above that Malay race was identified as majority passenger to use the train service, which is $38 \%$ from overall race. Chinese respondent composed of $12 \%$ followed by India's 17\% and others 33\% respectively.

Table 6. Cumulative Percentage of Race

\begin{tabular}{|l|l|l|l|l|}
\hline Valid & Frequency & Percent & $\begin{array}{l}\text { Valid } \\
\text { Percent }\end{array}$ & $\begin{array}{l}\text { Cumulative } \\
\text { Percent }\end{array}$ \\
\hline Malay & 96 & 38.4 & 38.4 & 38.4 \\
Chinese & 30 & 12.0 & 12.0 & 50.4 \\
Indian & 42 & 16.8 & 16.8 & 67.2 \\
Other & 82 & 32.8 & 32.8 & 100.0 \\
Total & 250 & 100.0 & 100.0 & \\
\hline
\end{tabular}

Source: SPSS Software

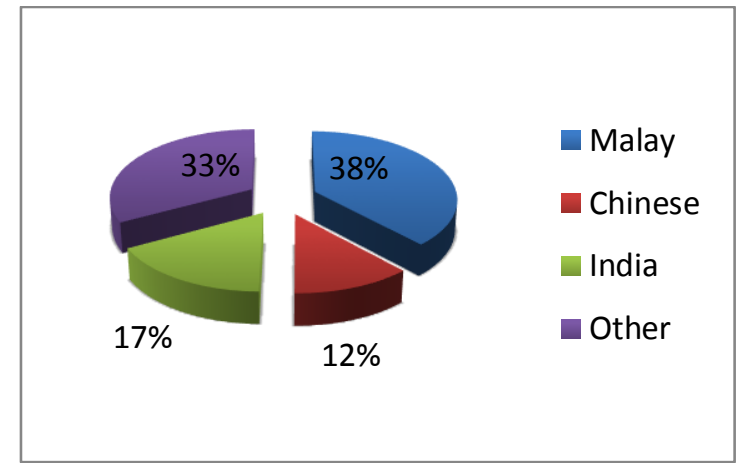

Figure 4. Race Characteristics

This research logit model was used to represent the decision-making procedure of an individual, in making a choice from a set of alternatives based on various influencing factors. The basic form of utility functions for current train and future train services in the mode choice analysis are as follows below:

$U=\alpha_{1}+\beta_{1}\left(T_{c}-T_{N}\right)+\beta_{2}\left(F_{c}-F_{N}\right)+$ $\beta_{3}\left(F r_{N}\right)$

where :

$\alpha_{1}=$ Constant (independent variable)

$\beta_{1}=$ Constant for travel time (dependent variables)

$\beta_{2}=$ Constant for frequency (dependent variables)

$\beta_{3}=$ Constant for fare (dependent variables)

$C=$ Current train

$N=$ New train

$T=$ Travel time

$F=$ Frequency

$F_{r}=$ Fares

Every model developed in this research is based on SPSS version 16.5 for windows with multiple regression method.

Figure 5 it can be determined that most of respondents prefer to choose scenario 2, where percentage is about $89.2 \%$. Evidence showed that the travelers for the trip purpose of school prefer to choose the train which can provides a better condition and affordable fares, although that scenario 2 maintain their travel time and frequency. The lowest percentage is for scenario 4 , which is only $46.7 \%$. This is 
because scenario 4 provide a longer waiting time.

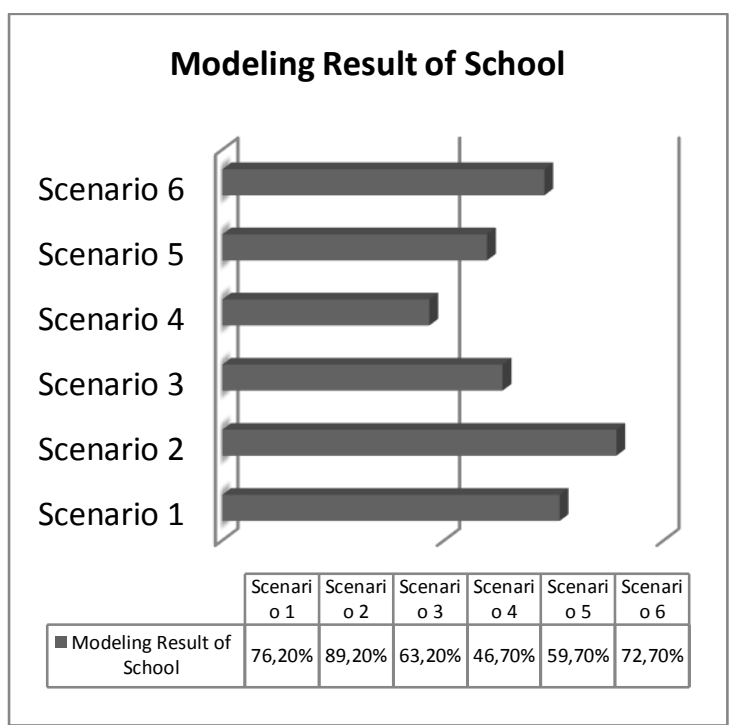

Figure 5. Chart percentage of school purpose

It can be concluded that a better safety and comfortability is not automatically attracted people to shifted or used train services. Since most of scenario applied lower fare in the future train as affordable price was implemented in the scenario reflect the traveler behaviour for the purpose of school trip to choose the new train services.

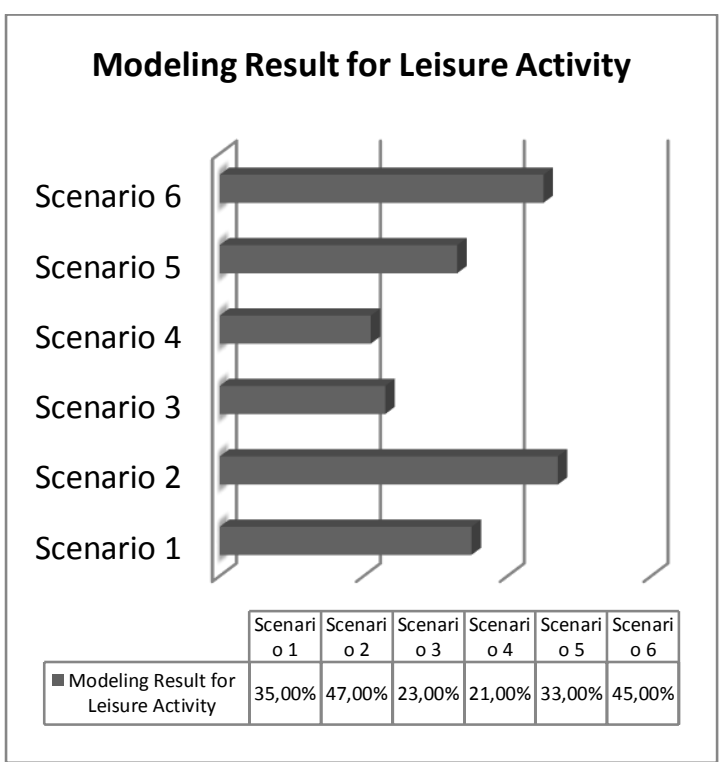

Figure 6. Chart percentage of leisure activity purpose
The commuter in Malaysia normally aiming the trip purpose in many category, one of the trip purposes is leisure activity that many travelers from Mantin to Kuala Lumpur utilized the commuter train services. Most of commuter train service users were college student who have initiative to travel for entertainment and leisure activity such as going to city center of Kuala Lumpur, shopping, and other recreational purpose. Based on the total trip percentage which was generated in this trip purpose shows less than $50 \%$ of respondents prefer to choose this mode due to limit of travelling purpose, then traveler sometimes only performed this trip at specific times such as weekend only. Figure 6 shows that most of the respondents prefer to choose scenario 2 , where the percentage is about $47 \%$. The different between both of the scenario are quite dissimilar instead of travel time, fares, comfort, and safety but the only frequency and fare remain the same. Scenario 4 provides a good condition of travel time ( $35 \mathrm{mins}$ ) with poor condition in comfortably and safety.

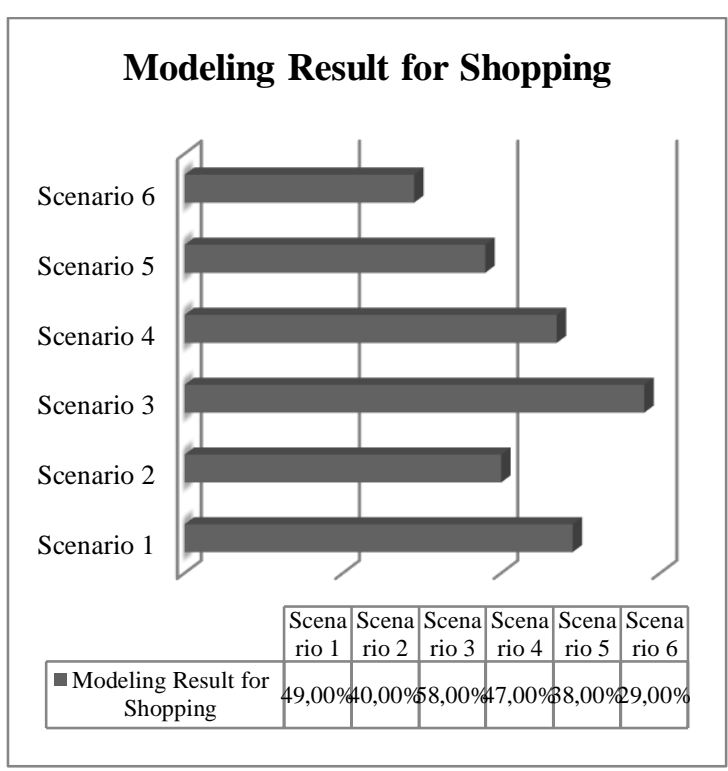

Figure 7. Chart percentage of shopping purpose

Trip purpose for shopping is not much different from leisure activity, because this activity is only done at certain times, even this activity is not done by 
everyone who uses the train service at every time. From the percentage result shown in figure 7 above that indicates the highest percentage generated by the scenario 3 with attribute of travel time is 50 minutes, frequency 30 minutes, and fare RM2.7, followed by good safety but least by a poor comfort remains.

This situation proved that travel time even better inclined with frequency of each train has been accelerated, but comfortability and safety conditions are always becomes significant factor in make decision. As these two services remains poor will lead to the traveler decision of not choose for this scenario. It is important for the traveler who only uses the train for shopping trip purpose to more concern about comfortable condition and for a safety concern.

From the summary of modeling result based on 6 scenarios, the research revealed that the most of the respondents prefer to choose scenario number 2 with the attribute such as travel time 50 minutes, frequency 10 minutes, fares RM2.70, good in comfort and safety given good as well.

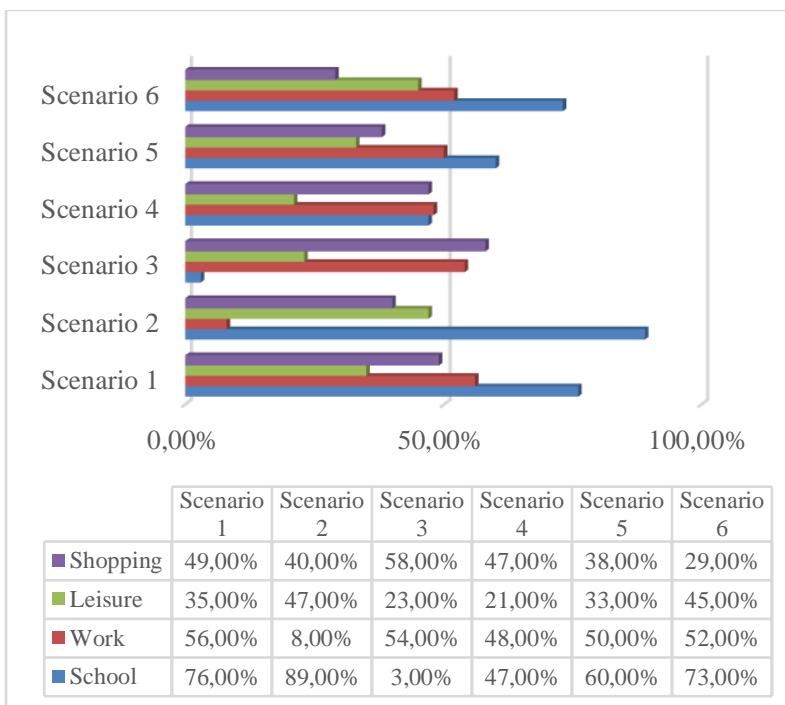

Figure 8. Summary modeling result of trip purpose

So based on scenario 2, it is determined that comfortable and safety for the journey of the public transportation especially in commuter services reflects the decision or behavior for most of the respondent preference. This research also was analyzed that the fares or cost reflects the behavior of the respondent to choose the new train services.

\section{CONCLUSION}

This research has been conducted with the mode choice modeling between current commuter and new services; behaviour in Mantin to Kuala Lumpur was examined through stated preference approach and binary logit model. Attributes studied were identified based on the concept of sustainable transportation.

Travel time, waiting time, safety and comfortable were found significant in modal split choice and this suggest the importance of integration design of transportation plan, communities and land use planning. Travel time and waiting time are considered, as frequency results are in consistent with other findings with their influence in mode choice.

All respondent in this research gave a good response and positive feedback to the questionnaire distributed. In situation where time does not affect the course of using trip-planning decisions, then that individual may be trying to make the best use of time travel on the selected mode. Some attribute might be a give an impact and influence the preference of respondents while the time travel, frequency, fares, comfort, and safety are improves.

\section{REFERENCES}

1. Kroes, E.P., Stated Preferences Microsimulation Model From Qualitative Inputs to Estimate Market Shares in InterCity Travel, Proceeding of The ESOMAR Congress, Monte Carlo, 1998.

2. Well, G.R, Comprehensive Transport Planning. London, Charles Griffin. United Kingdom, Book of Ofyar. Z. Tamin. ITB, Bandung, Indonesia, 1997.

3. Resdiansyah, Development of An Expert Advisory System For Strategy Implementation In Transports Demand 
Management (E-ASSIST), Ph.D research thesis, University Kebangsaan Malaysia, 2011. 